\title{
Modulation of Acid Sphingomyelinase in Melanoma Reprogrammes the Tumour Immune Microenvironment
}

\author{
Emma Assi, ${ }^{1,2}$ Davide Cervia, ${ }^{3,4}$ Laura Bizzozero, ${ }^{1,5}$ Annalisa Capobianco, ${ }^{6}$ \\ Sarah Pambianco, ${ }^{3}$ Federica Morisi, ${ }^{3}$ Clara De Palma, ${ }^{3}$ Claudia Moscheni, ${ }^{7}$ \\ Paolo Pellegrino, ${ }^{3}$ Emilio Clementi, ${ }^{1,3}$ and Cristiana Perrotta ${ }^{3}$
}

\author{
${ }^{1}$ Scientific Institute IRCCS Eugenio Medea, 23842 Bosisio Parini, Italy \\ ${ }^{2}$ Division of Molecular Oncology, San Raffaele Scientific Institute, 20132 Milan, Italy \\ ${ }^{3}$ Unit of Clinical Pharmacology, National Research Council-Institute of Neuroscience, Department of Biomedical and \\ Clinical Sciences "Luigi Sacco" (DIBIC), University Hospital "Luigi Sacco", Università di Milano, 20157 Milan, Italy \\ ${ }^{4}$ Department for Innovation in Biological, Agro-Food and Forest Systems (DIBAF), Università della Tuscia, 01100 Viterbo, Italy \\ ${ }^{5}$ Department of Oncology, Università di Torino and Laboratory of Neurovascular Biology, Candiolo Cancer Institute, \\ 10060 Candiolo, Italy \\ ${ }^{6}$ Division of Regenerative Medicine, San Raffaele Scientific Institute, 20132 Milan, Italy \\ ${ }^{7}$ Unit of Morphology, Department of Biomedical and Clinical Sciences "Luigi Sacco" (DIBIC), Università di Milano, \\ 20157 Milan, Italy
}

Correspondence should be addressed to Emilio Clementi; emilio.clementi@unimi.it and Cristiana Perrotta; cristiana.perrotta@unimi.it

Received 24 February 2015; Revised 24 April 2015; Accepted 27 April 2015

Academic Editor: Anshu Agrawal

Copyright (C) 2015 Emma Assi et al. This is an open access article distributed under the Creative Commons Attribution License, which permits unrestricted use, distribution, and reproduction in any medium, provided the original work is properly cited.

\begin{abstract}
The inflammatory microenvironment induces tumours to acquire an aggressive and immunosuppressive behaviour. Since acid sphingomyelinase (A-SMase) downregulation in melanoma was shown to determine a malignant phenotype, we aimed here to elucidate the role of A-SMase in the regulation of tumour immunogenic microenvironment using in vivo melanoma models in which A-SMase was either downregulated or maintained at constitutively high levels. We found high levels of inflammatory factors in low A-SMase expressing tumours, which also displayed an immunosuppressive/protumoural microenvironment: high levels of myeloid-derived suppressor cells (MDSCs) and regulatory T lymphocytes (Tregs), as well as low levels of dendritic cells (DCs). In contrast, the restoration of A-SMase in melanoma cells not only reduced tumour growth and immunosuppression, but also induced a high recruitment at tumour site of effector immune cells with an antitumoural function. Indeed, we observed a poor homing of MDSCs and Tregs and the increased recruitment of $\mathrm{CD}^{+}$and $\mathrm{CD} 4^{+} \mathrm{T}$ lymphocytes as well as the infiltration of DCs and $\mathrm{CD}^{+} / \mathrm{CD} 44^{\text {high }} \mathrm{T}$ lymphocytes. This study demonstrates that change of A-SMase expression in cancer cells is sufficient per se to tune in vivo melanoma growth and that A-SMase levels modulate immune cells at tumour site. This may be taken into consideration in the setting of therapeutic strategies.
\end{abstract}

\section{Introduction}

Malignant melanoma is a highly metastatic skin cancer characterized by rapid growth, early metastasis, and resistance to chemotherapy and radiotherapy [1]. In the past the high immunogenic capacity of melanoma has fostered the development of immunotherapeutic strategies based on the stimulation of adaptive immunity $\mathrm{T}$ cell mediated against specific tumour antigen [2]. However, despite initial promising studies, the overall outcomes of the clinical trials based on immunotherapy are still far from being satisfying [3]. The lack of an effective immune reactivity to tumours may be explained by the protracted inflammation that occurs in melanoma microenvironment, eventually resulting in 
immunosuppression and thus in the failure of immune cells to reject the tumour $[4,5]$. The inflammatory microenvironment in the tumour mass is the result of the secretion of inflammatory cytokines by both melanoma and stromal cells $[6,7]$. It induces cancer cells to acquire a more aggressive phenotype and allows the recruitment in the tumour lesion of different immunosuppressive cells, such as myeloid-derived suppressor cells (MDSCs) and, consequently, regulatory $\mathrm{T}$ lymphocytes (Tregs) [5]. Various strategies have been used to decrease MDSC amounts and immunosuppressive functions in tumours, including melanomas $[4,8,9]$. However, the molecular mechanisms leading to the control of intratumoural MDSCs are poorly understood. The elucidation of these aspects may be crucial for the development of new approaches in melanoma treatment aimed at reducing MDSC-mediated immunosuppression.

In the last decades, the proapoptotic second messenger ceramide has drawn the attention as a fundamental player in cancer biology $[10,11]$. Ceramide levels are significantly decreased in several tumours including melanomas, colon cancers, ovarian cancers, and gliomas; interestingly an inverse relationship has been found between ceramide levels and the stratification of tumours with high- and lowgrade gliomas containing low and high levels of ceramide, respectively [12-14]. Of interest it seems particularly clear that cancer cells have evolved complex mechanisms to reduce ceramide levels, possibly through the modulation of their generating enzymes [15-17]. An example of this event is the spontaneous downregulation of the ceramide-generating enzyme acid sphingomyelinase (A-SMase) in melanoma cells during tumour progression that accounts for a more aggressive behaviour of melanomas in terms of tumour growth and metastatic ability [18].

This work has been designed to elucidate the possible role of A-SMase in determining melanoma immunogenic capacity with a specific attention on the modulation of tumour microenvironment. To this end, we analysed the immune cell infiltration in a mouse model of melanoma syngeneic transplant that is particularly aggressive and, more importantly, that recapitulates the downregulation of A-SMase during tumour progression [18]. A clone in which A-SMase is maintained at constitutively high levels during melanoma progression was analysed as well. We found that the progressive loss of A-SMase enhanced the immunosuppressive capacity of melanoma cells through the recruitment of MDSCs and Tregs at tumour site and the impairment of dendritic cells (DCs) maturation. Of importance, the upregulation of A-SMase enhanced the function of immune effector cells as DCs and cytotoxic T lymphocytes. This A-SMase-dependent modulation of microenvironment events may have a therapeutic outcome in terms of tumour growth.

\section{Methods}

2.1. Cell Models and Animals. The cell clones used in our experiments were generated from the murine melanoma cell line B16-F1 of American Type Culture Collection (LGC Standards, Sesto San Giovanni, Italy). As described in
Bizzozero et al. [18], the low expressing A-SMase B16W6_pSIL10 clone was generated from a subclone of the parental cell line B16-F1 (i.e., B16-W6) by transfecting the cells with the plasmid pSilencer4.1-CMV (Invitrogen-Life Technologies, Monza, Italy) harbouring a shRNA containing a sequence which gave the A-SMase silencing. The control clone used in our experiments (B16-pSILscr) was generated by transfecting B16-W6 cells with the plasmid pSilencer4.1CMV harbouring a shRNA containing a scrambled sequence. The B16-B1A clone overexpressing A-SMase was generated as follows: the pEF1/Myc plasmid (Invitrogen-Life Technologies) containing cDNA for A-SMase [18] was transfected in B16-F1 cells using the Fugene transfection reagent (Promega, Milano, Italy), according to the manufacturer's protocol. Approximately 15 colonies resistant to the antibiotic G418 $(500 \mu \mathrm{g} / \mathrm{mL})$ were tested for A-SMase expression and activity (see Section 3.3). A B16-F1 clone transfected with the empty vector pEF1/Myc (B16-pEF1) was used as control. Cells were routinely tested for Mycoplasma using a BioWhittaker MycoAlert Mycoplasma Detection Kit (Lonza Group, Basel, Switzerland). Cells were cultured in Iscove's modified Dulbecco's medium supplemented with $10 \%$ heatinactivated foetal bovine serum (FBS), glutamine $(200 \mathrm{mM})$, and penicillin/streptomycin $(100 \mathrm{U} / \mathrm{mL})$ and grown at $37^{\circ} \mathrm{C}$ in a humidified atmosphere containing $5 \% \mathrm{CO}_{2}$.

Female C57BL/ 6 mice (6-8 weeks old) were purchased from Charles River Laboratories (Calco, Italy), housed in a regulated environment $\left(23 \pm 1^{\circ} \mathrm{C}, 50 \pm 5 \%\right.$ humidity $)$ with a $12 \mathrm{~h}$ light/dark cycle (lights on at 08.00 a.m.), and provided with food and water ad libitum. All studies were conducted in accordance with the Italian law on animal care $\mathrm{N}^{\circ}$ 116/1992 and the European Communities Council Directive EEC/609/86. The experimental protocols were approved by the Ethics Committee of the University of Milan. All efforts were made to reduce both animal suffering and the number of animals used.

2.2. Animal Handling and Tumour Growth. Mice received s.c. injections of $5 \times 10^{4}$ cells in the lower-right flank on day 0 (ten animals per group at minimum) $[18,19]$. Tumour growth was monitored every 2-3 days by means of external calliper measurements and volume calculation (length $\times$ width $^{2} / 2$ ), until mice reached IACUC euthanasia criteria, as, for instance, clinical signs of tumour or when tumour size exceeded $10 \%$ of body weight [19]. For PCR and flow cytometry analysis tumours were resected when they reached the volume of ca. $500 \mathrm{~mm}^{3}$. Late stage melanomas were explanted at a volume of ca. $1500 \mathrm{~mm}^{3}$.

2.3. Quantitative Real Time-PCR (qPCR). The analysis of mRNA expression was performed as previously described [18, 20-22]. Briefly, total RNA from resected tumours and in vitro B16 clones was extracted with the High Pure RNA Tissue Kit and the High Pure RNA Isolation Kit, respectively (Roche Applied Science, Mannheim, Germany), according to the manufacturer's protocol. First-strand cDNA was generated from $1 \mu \mathrm{g}$ of total RNA using iScript Reverse Transcription Supermix (Bio-Rad, Hercules, CA, USA). As shown in 
TABLE 1: Primer pairs designed for PCR analysis.

\begin{tabular}{|c|c|c|c|c|}
\hline Name & Symbol & Accession number & Primer sequence & Amplicon \\
\hline IL- $1 \beta$ & $i l 1 b$ & NM_008361 & $\begin{array}{c}\text { F: 5'-GCAACTGTTCCTGAACTCAACT-3' } \\
\text { R: 5'-ATCTTTTGGGGTCCGTCAACT-3' }\end{array}$ & 89 bp \\
\hline IL-6 & $i l 6$ & NM_031168 & $\begin{array}{c}\text { F: } 5^{\prime} \text {-TAGTCCTTCCTACCCCAATTTCC-3' } \\
\text { R: } 5^{\prime} \text {-TTGGTCCTTAGCCACTCCTTC-3' }\end{array}$ & 76 bp \\
\hline Il-10 & il10 & NM_010548 & $\begin{array}{c}\text { F: 5'-GCTCTTACTGACTGGCATGAG-3' } \\
\text { R: 5'-CGCAGCTCTAGGAGCATGTG-3' }\end{array}$ & $105 \mathrm{bp}$ \\
\hline GM-CSF & $\operatorname{csf} 2$ & NM_009969 & $\begin{array}{c}\text { F: } 5^{\prime} \text {-GGCCTTGGAAGCATGTAGAGG-3' } \\
\text { R: } 5^{\prime} \text {-GGAGAACTCGTTAGAGACGACTT-3' }\end{array}$ & $104 \mathrm{bp}$ \\
\hline TGF- $\beta 1$ & $\operatorname{tg} f b 1$ & NM_011577 & $\begin{array}{c}\text { F: } 5^{\prime}-\text { AAACGGAAGCGCATCGAA- }{ }^{\prime} \\
\text { R: } 5^{\prime}-\text { GGGACTGGCGAGCCTTAGTT- } 3^{\prime}\end{array}$ & $63 \mathrm{bp}$ \\
\hline TNF- $\alpha$ & $\operatorname{tnf}$ & NM_013693 & $\begin{array}{l}\text { F: 5'-TTCTGTCTACTGAACTTCGGGGTGATCGGTCC-3' } \\
\text { R: 5'-GTATGAGATAGCAAATCGGCTGACGGTGTGGG-3' }\end{array}$ & $354 \mathrm{bp}$ \\
\hline GAPDH & gapdh & NM_008084 & $\begin{array}{l}\text { F: } 5^{\prime} \text {-ACCCAGAAGACTGTGGATGG-3' } \\
\text { R: } 5^{\prime} \text {-ACACATTGGGGGTAGGAACA-3 }\end{array}$ & $172 \mathrm{bp}$ \\
\hline A-SMase(v.1,2) & $\operatorname{smpd1}$ & $\begin{array}{c}\text { NM_000543; } \\
\text { NM_001007593 }\end{array}$ & $\begin{array}{c}\text { F: } 5^{\prime} \text {-TGGCTCTATGAAGCGATGGC-3' } \\
\text { R: } 5^{\prime} \text {-TTGAGAGAGATGAGGCGGAGAC-3' }\end{array}$ & $125 \mathrm{bp}$ \\
\hline
\end{tabular}

F: forward; R: reverse.

Table 1, a set of primer pairs amplifying fragments ranging from 63 to 354 bp was designed to hybridise to unique regions of the appropriate gene sequence. qPCR was performed using SsoAdvanced Universal SYBR Green Supermix (Bio-Rad). The fold change was determined relative to the control after normalising to GAPDH (internal standard) through the use of the formula $2^{-\Delta \Delta C T}$.

2.4. Flow Cytometry. After surgical excision, a single cell suspension from tumours was obtained by collagenase IV $(0.2 \mathrm{mg} / \mathrm{mL})$, dispase $(2 \mathrm{mg} / \mathrm{mL})$, and DNase I $(0.1 \mathrm{mg} / \mathrm{mL})$ treatment in Iscove's modified Dulbecco's medium, supplemented with 5\% FBS, glutamine $(200 \mathrm{mM})$, and penicillin/streptomycin $(100 \mathrm{U} / \mathrm{mL})$. After $30 \mathrm{~min}$ at $37^{\circ} \mathrm{C}$ in a shaking bath, the cell suspension was filtered ( $40 \mu \mathrm{m}$ poresize membrane) and washed in phosphate buffer saline (PBS) added with $1 \%$ bovine serum albumin (BSA). Unspecific sites were blocked incubating samples for $20 \mathrm{~min}$ at room temperature in PBS containing 10\% goat serum and 1\% BSA. Cells were then incubated with fluorophore-conjugated antibodies for the staining of specific cellular markers (Table 2) in $1 \%$ BSA-PBS solution (1 h on ice). Cells were analysed by flow cytometry using a Gallios Flow Cytometer (BeckmanCoulter, Brea, CA, USA) and the software FCS Express 4 (De Novo System, Portland, OR, USA).

2.5. Western Blotting. The analysis of protein expression from in vitro B16 clones was performed as previously described $[18,20-23]$. The rabbit polyclonal anti myc-tag (Cell Signaling Technology, Danvers, MA, USA) and the mouse monoclonal anti-TATA binding protein (TBP) (Abcam, Cambridge, UK) primary antibodies were used in combination with the appropriate secondary antibodies HRP-conjugated (Bio-Rad). Proteins were visualised using Bio-Rad Clarity Western ECL substrate with a Bio-Rad ChemiDoc MP imaging system. Bands were quantified for densitometry using the Bio-Rad Image Lab software.
TABLE 2: List of the antibodies used in flow cytometry for immune cells analysis.

\begin{tabular}{lcc}
\hline Protein name & Conjugation & Clone \\
\hline CD11b & APC & M1/70.15.11.5 \\
Gr1 & FITC & RB6-8C5 \\
CD4 & PE-Cy5 & GK1.5 \\
CD8 & PE-Cy5 & eBioH35-17.2 \\
CD44 & PE-Cy7 & IM7 \\
CD25 & PE-Cy7 & PC61.5 \\
Foxp3 & PE & $150 \mathrm{D} / \mathrm{E} 4$ \\
CD11c & PE & N418 \\
CD80 & FITC & $16-10 A 1$ \\
MHCII & PE-Cy5 & M5/114.15.2 \\
\hline
\end{tabular}

2.6. A-SMase Activity. Cells $\left(2 \times 10^{6}\right.$ cells $\left./ \mathrm{mL}\right)$ were homogenised in the acid lysis buffer $(50 \mathrm{mM}$ sodium acetate, $1 \%$ Triton X-100, and $1 \mathrm{mM}$ EDTA, pH 5) with freshly added protease inhibitor cocktail (cOmplete, Roche Applied Science) [24]. Sphingomyelinase activity was measured using the Amplex Red Sphingomyelinase Assay Kit (Molecular Probes-Life Technologies, Monza, Italy), as described in the manufacturer's protocol.

2.7. Apoptosis Detection. Apoptosis was measured by flow cytometry as described previously [18]. Briefly, adherent cells were detached using Enzyme-Free Cell Dissociation Buffer (Merck Millipore Billerica, MA, USA), washed twice with cold PBS, and incubated $\left(1 \times 10^{6}\right.$ cells $)$ with $5 \mu \mathrm{L}$ of FITC-labelled annexin V (Life Technologies, Monza, Italy) to detect phosphatidylserine exposure on the outer leaflet of the plasma membrane and $5 \mu \mathrm{L}$ of propidium iodide (PI) (eBioscience, San Diego, CA, USA) to exclude necrotic cells, in binding buffer (10 mM HEPES, $140 \mathrm{mM} \mathrm{NaCl}$, and $2.5 \mathrm{mM}$ $\mathrm{CaCl}_{2}$ ). After $15 \mathrm{~min}$ of incubation at room temperature, cells 
were acquired using a Gallios Flow Cytometer (BeckmanCoulter, Brea, CA, USA) and analysed by the software FCS Express 4 (De Novo System, Portland, OR, USA).

2.8. Statistical Analysis. Upon verification of normal distribution, statistical significance of raw data between the groups in each experiment was evaluated using unpaired Student's t-test (single comparisons) or one-way ANOVA followed by the Newman-Keuls posttest (multiple comparisons). Data belonging from different experiments were represented and averaged in the same graph. Tumour growth was analysed using two-way ANOVA, followed by the Bonferroni posttest. The GraphPad Prism software package (Graph Software, San Diego, CA, USA) was used. Results are expressed as means \pm standard error of the mean (SEM) of the indicated $n$ values.

2.9. Materials. Iscove's modified Dulbecco's medium, FBS, glutamine, penicillin/streptomycin, HEPES, G418, and PBS were purchased from Euroclone (Pero, Italy). Primer pairs were obtained from Primm Biotech (Milano, Italy). Dispase and DNase I were obtained from Gibco-Life Technologies (Monza, Italy) and Roche Applied Science, respectively. Goat serum was purchased from Vector Laboratories (Burlingame, CA, USA). Flow cytometry antibodies were purchased as follows: CD11b and Gr1 from Miltenyi Biotec, Bergisch Gladbach, Germany; CD11c, CD80, MHCII, CD4, CD8, CD25, CD44, and Foxp3 from eBioscience, San Diego, CA, USA. All other reagents were purchased from Sigma-Aldrich (Saint Louis, MO, USA).

\section{Results}

3.1. Downregulation of A-SMase Increases the Accumulation of MDSCs in Melanoma. We have previously demonstrated that during B16-F1 melanoma progression A-SMase is spontaneously downregulated thus conferring to melanoma cells a more aggressive phenotype [18]. To evaluate the impact of this event on the modulation of tumour microenvironment, mice were subcutaneously injected with B16-W6_pSIL10 cells, a loss-of-function model of A-SMase obtained by the knockdown of A-SMase in the parental cell line B16-F1 [18]; we then analysed the in vivo behaviour of the established skin melanoma in terms of cytokine expression and tumourinfiltrating immune cells. The parental cell line B16-pSILscr served as control.

The mRNA analysis by qPCR in the explanted melanomas of a panel of different inflammatory factors showed a significant accumulation at B16-W6_pSIL10 tumour site of interleukin- (IL-) 1 $\beta$, IL-6, IL-10, granulocyte-macrophage colony-stimulating factor (GM-CSF), transforming growth factor- (TGF-) $\beta 1$, and tumour necrosis factor- (TNF-) $\alpha$ (Figure 1(a)). A sustained secretion and maintenance of inflammatory mediators during tumour progression stimulate the enrichment and activation of MDSCs then leading to immunosuppression [4]. Thus, we evaluated the presence of MDSCs (CD11b ${ }^{+} / \mathrm{Grl}^{+}$cells) in the tumour mass by flow cytometry. As shown in Figure 1(b), we found a significant

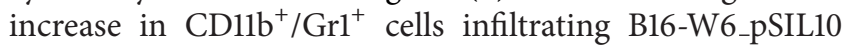
tumours with respect to control. Of notice, the percentage of MDSCs in B16-F1 tumours at a late stage of growth, in which A-SMase was spontaneously downregulated [18], was similar to that of B16-W6_pSIL10 tumours (Supplementary Figure 1(a) in Supplementary Material available online at http://dx.doi.org/10.1155/2015/370482). These observations support the role of A-SMase downregulation in favouring the recruitment of MDSCs at the tumour lesion.

3.2. A-SMase-Related MDSC Accumulation Determines an Immunosuppressive Microenvironment. MDSCs exert their immunosuppressive function through the impairment of DCs (CD11c ${ }^{+}$cells) and cytotoxic T lymphocytes (CD8 ${ }^{+}$cells) [25-27] and the recruitment of Tregs $\left(\mathrm{CD} 4^{+} / \mathrm{CD} 25^{+} / \mathrm{Foxp}^{+}\right.$ cells) [40]. Flow cytometry analysis of immune cells from explanted melanomas showed a significant decrease of CD11c $^{+}$cells at B16-W6_pSIL10 tumour site when compared to control (Figure 2(a)). Interestingly recruited DCs displayed an immature and anergic phenotype as indicated by the reduction of the costimulatory markers CD80 and MHCII (Figure 2(b)). Although we did not observe a difference in $\mathrm{CD}^{+}$and $\mathrm{CD}^{+} \mathrm{T}$ infiltrating lymphocytes (Figures 2(c) and 2(d)), we found a significant increase in the number of Tregs in B16-W6_pSIL10 tumours with respect to control (Figure 2(e)). Similar results were obtained in B16-F1 melanoma at late stage of growth (Supplementary Figure 1(b)). Taken together, these results indicate that a low expression of A-SMase in melanoma cells induces an immunosuppressive tumour microenvironment.

\subsection{Restoring A-SMase Expression Switches the Tumour} Microenvironment from a Pro- to an Antitumoural Phenotype and Reduces Melanoma Growth. To demonstrate unambiguously that A-SMase expression by melanoma cells modulates tumour microenvironment, different gain-of-function models of A-SMase were generated by stable transfection of A-SMase in B16-F1 cells. Measurements of A-SMase mRNA (Figure 3(a)), protein expression (Figure 3(b)), and activity (Figure 3(c)) in these A-SMase transfected clones with respect to parental control (B16-pEF1) allowed us to select B16-B1A as the cells overexpressing A-SMase to be used for in vivo studies as follows. In particular, mice were subcutaneously injected with B16-B1A cells and the explanted melanomas analysed for A-SMase expression and the immune cell composition. The cell clone B16-pEF1 served as control. As expected, B16-B1A tumour maintained stable levels of A-SMase mRNA levels during growth (Figure 4(a)). Of interest, the number of MDSCs and Tregs decreased significantly in B16-B1A tumour when compared to control (Figures 4(b) and 4(c)). This event was paralleled by the increase of DCs infiltrate (Figure 5(a)). These cells partially recovered their maturation status as demonstrated by the increase in expression of the costimulatory markers CD80 and MHCII (Figure 5(b)). Unexpectedly, even $\mathrm{CD}^{+}$and $\mathrm{CD}^{+} \mathrm{T}$ infiltrating lymphocytes as well as the $\mathrm{CD} 8^{+} / \mathrm{CD} 44^{\text {high }}$ activated T lymphocytes were significantly higher in B16-B1A tumours with respect to B16-pEF1 ones (Figures 5(c)-5(e)); no differences were observed in the population of $\mathrm{CD} 4^{+} / \mathrm{CD} 44^{\text {high }} \mathrm{T}$ lymphocytes (Figure 5(f)). These data indicate that A-SMase 

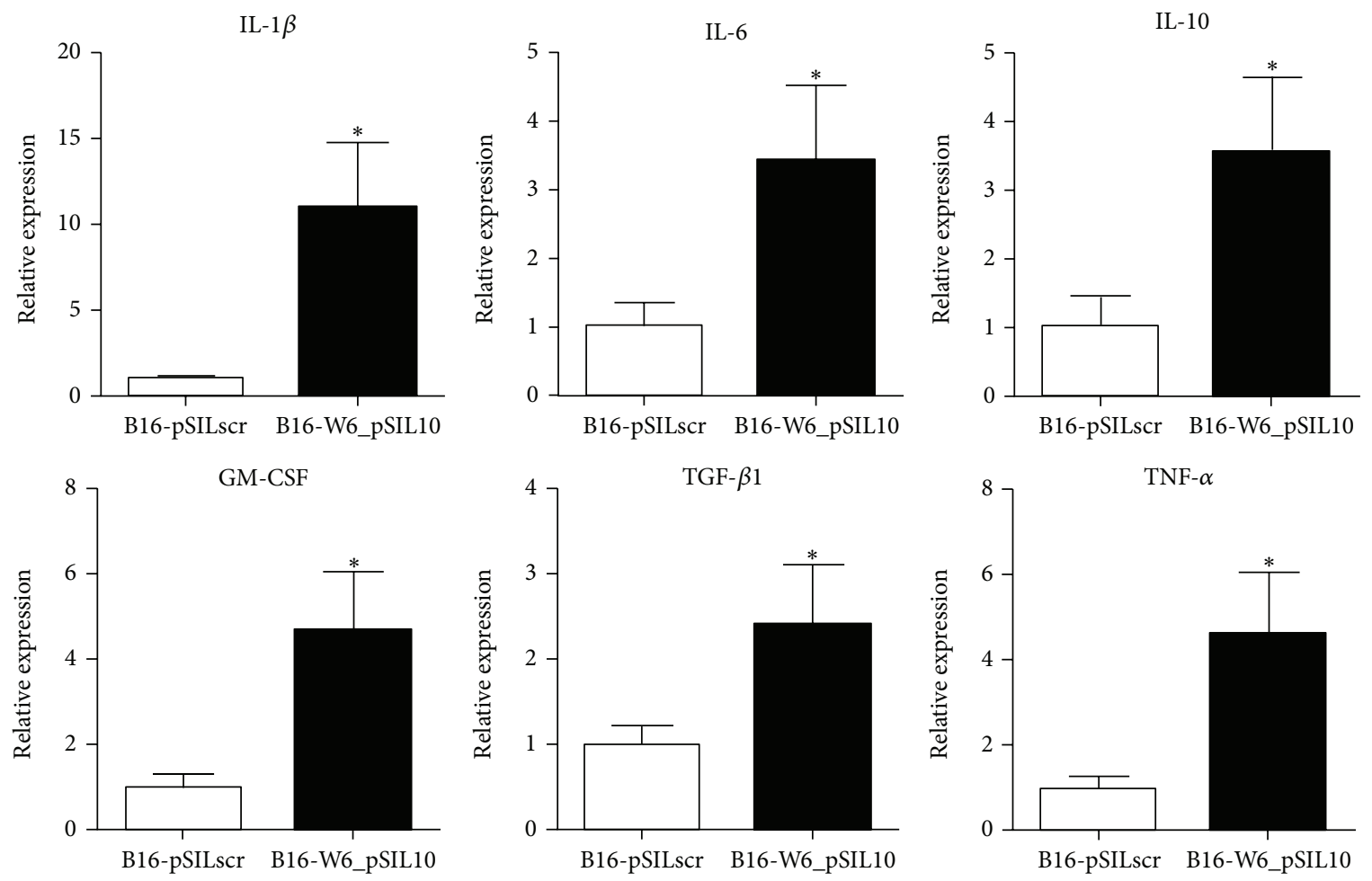

(a)
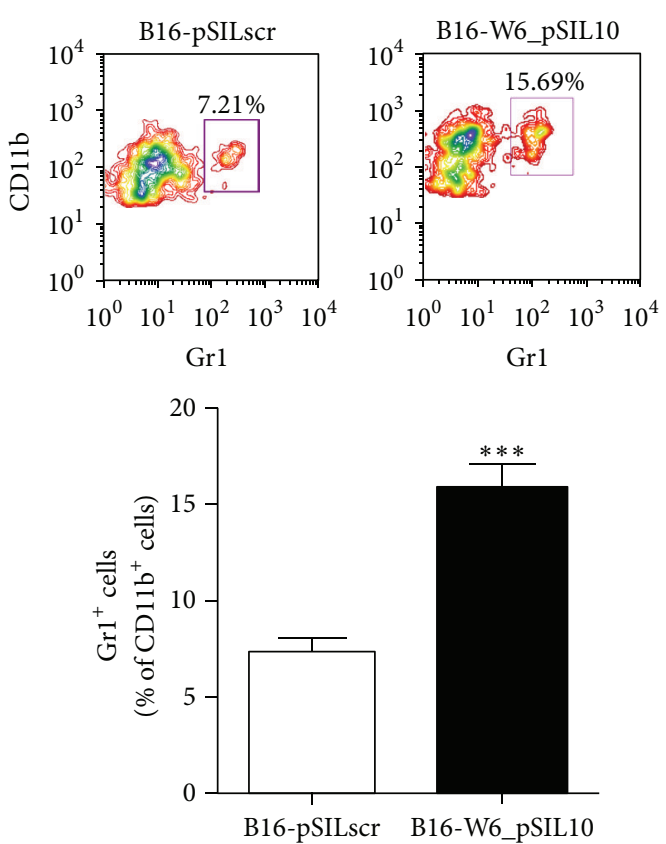

(b)

FIGURE 1: Downregulation of A-SMase increases the accumulation of MDSCs in melanoma. Tumours were resected when they reached the volume of ca. $500 \mathrm{~mm}^{3}$ and treated to extract mRNA or obtain a cell suspension. (a) qPCR analysis of mRNA of IL-1 $\beta$, IL-6, IL-10, GM-CSF, TGF- $\beta 1$, and TNF- $\alpha$. The histograms are representative of results obtained from at least seven to twelve different animals per experimental group. (b) Flow cytometry analysis of tumour-infiltrating immune cells. The cell suspensions obtained from different tumours were stained with anti-CD11b-APC and anti-Gr1-FITC antibodies. A representative dot plot of $\mathrm{CD}_{11 \mathrm{~b}}{ }^{+} / \mathrm{Grl}^{+}$cells in the CD11b population cell is shown (upper panel). The histograms represent the results obtained from at least ten to fifteen different animals per experimental group (lower panel). Values are expressed as mean \pm SEM. ${ }^{* * *} P<0.001$ versus B16-pSILscr control. 

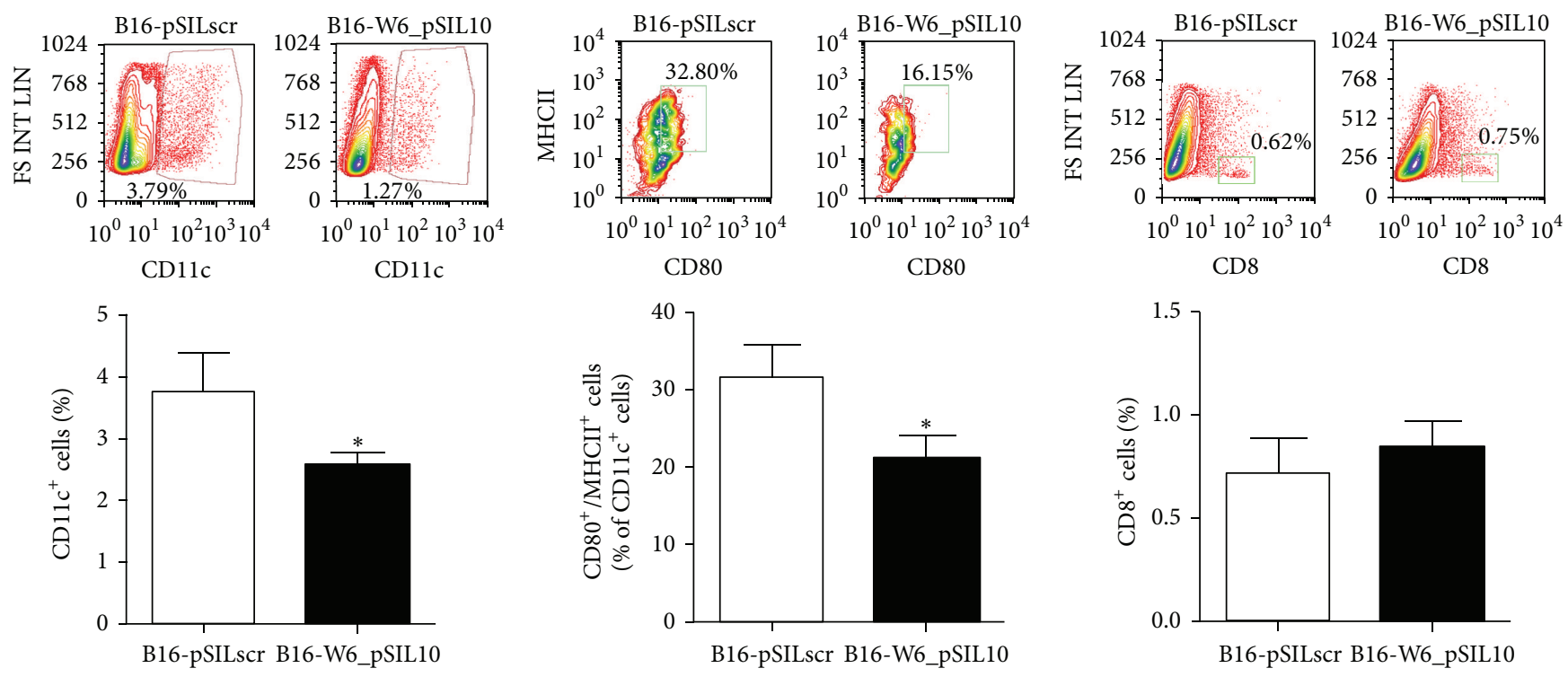

(a)

(b)

(c)

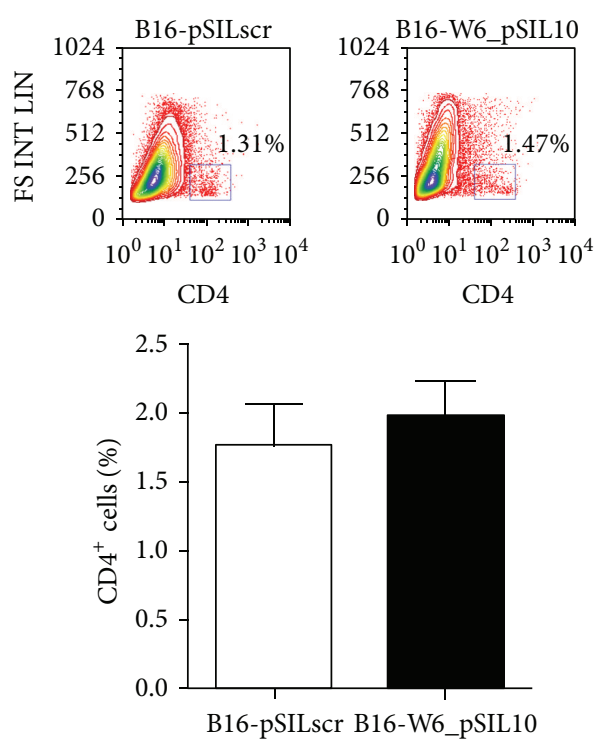

(d)
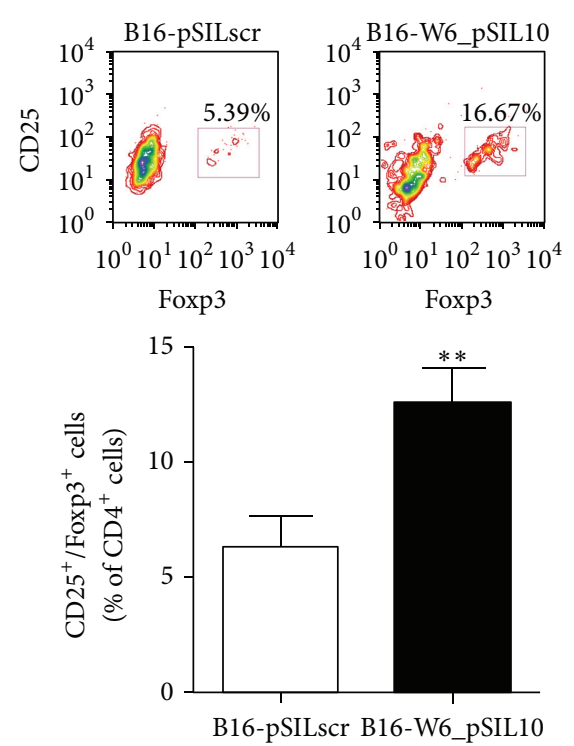

(e)

FIGURE 2: A-SMase induced MDSC accumulation determines an immunosuppressive microenvironment. Flow cytometry analysis of tumourinfiltrating immune cells. Tumour cell suspensions obtained from resected tumours were stained with the specific fluorescent conjugated antibodies for CD11c, CD80, MHCII, CD8, CD4, CD25, and Foxp3 antibodies. (a) A representative dot plot of gated CD11c ${ }^{+}$cells is shown (upper panel). The histograms represent the data obtained from ten to fifteen animals per experimental group (lower panel). (b) A representative dot plot of $\mathrm{CD}^{+} 0^{+} / \mathrm{MHCII}^{+}$cells in the $\mathrm{CD} 11 \mathrm{c}^{+}$cell population is shown (upper panel). The histograms represent the data obtained from ten to fifteen animals per experimental group (lower panel). (c-d) A representative dot plot of CD8 ${ }^{+}$cells (c) and CD4 ${ }^{+}$cells (d) is shown (upper panel). The histograms represent the data obtained from ten to fifteen animals per experimental group (lower panel). (e) A representative dot plot of $\mathrm{CD}_{2} 5^{+} / \mathrm{Foxp}^{+}$in the $\mathrm{CD} 4^{+}$cell population is shown (upper panel). The histograms represent the data obtained from ten to fifteen animals per experimental group (lower panel). Values in each histogram are expressed as mean \pm SEM. ${ }^{*} P<0.05$; ${ }^{* *} P<0.01$ versus B16-pSILscr control.

restoration in melanoma cells results in the establishment of an antitumoural microenvironment through both the reduction of protumoural immune cells and the recruitment of antitumoural immune cells at tumour site.

Finally we addressed whether the overexpression of A-SMase may have therapeutic efficacy. The analysis of melanoma apoptosis in vitro revealed that the higher levels of
A-SMase in B16-B1A correlate with an increase of apoptotic cell number when compared to the B16-pEF1 control cells (Figure 6(a)), thus confirming the fundamental role played by A-SMase in sensitivity to apoptosis. Of notice, as shown in the growth analysis in vivo of Figure 6, we observed a significant delay in the outgrowth of B16-B1A tumours versus control. These data are in line with our previous results in which the 


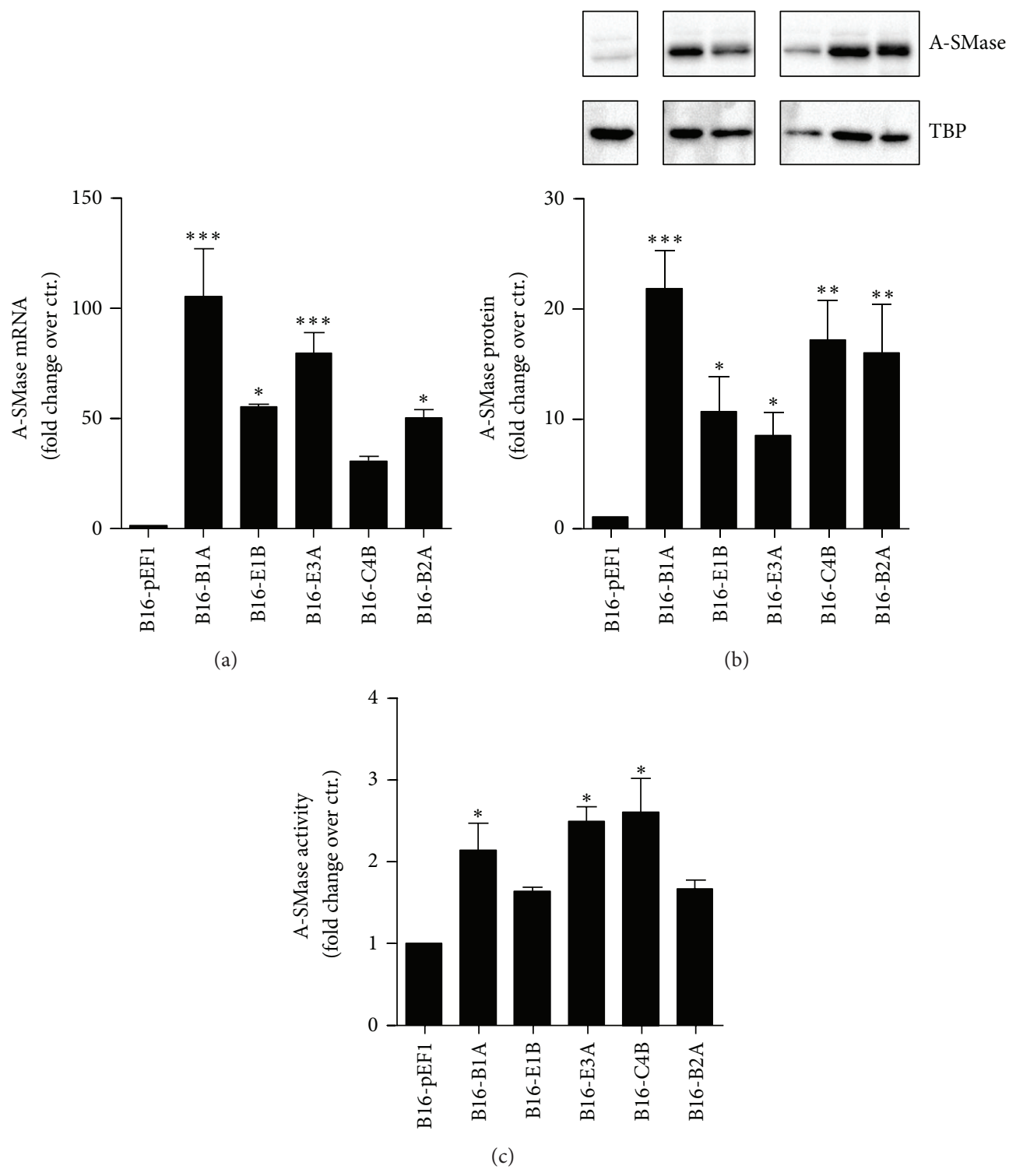

Figure 3: Generation of B16-F1 clones stably expressed A-SMase. Evaluation of A-SMase expression/activity in B16-F1-derived clones overexpressing A-SMase. The B16-pEF1 clone transfected with the empty vector (pEF1) was used as control. (a) qPCR analysis of A-SMase expression. (b) Western blotting analysis of A-SMase. Image is representative of at least three independent experiments. TBP was used as loading control. The histograms represent the densitometric values normalized on TBP. (c) A-SMase activity on cell lysates measured as sphingomyelin hydrolysis at $\mathrm{pH} 5.5$. Values are expressed as fold increases over control $\pm \operatorname{SEM}(n=3) .{ }^{*} P<0.05 ;{ }^{* *} P<0.01 ;{ }^{* * *} P<0.001$ versus B16-pEF1 control.

silencing of A-SMase resulted in an increase in melanoma growth [18] and confirms the inverse correlation between ASMase expression and melanoma progression.

\section{Discussion}

The role of A-SMase in the response of tumours to chemotherapy and radiotherapy is a well-established concept [14]. Indeed, the enzyme contributes significantly to the cytotoxic effects of several anticancer drugs such as cisplatin, retinoids, and doxorubicin [28-32]. Moreover it has been demonstrated that the peritumoural injection of recombinant A-SMase sensitises mouse subcutaneous melanomas to the antineoplastic effects of radiotherapy [33]. Recently, A-SMase downregulation was shown to favour human and mouse melanoma ability to grow, invade, and metastasise [18]. We now show that change of A-SMase expression in cancer cells is sufficient per se to tune in vivo melanoma growth. In addition, our data indicated that A-SMase levels modulate immune cells at tumour site, thus suggesting the role of ASMase as an immune-regulating factor of melanoma tumour microenvironment.

It is well known that the interactions between immune system components recruited into the tumour microenvironment are crucial for tumour development and progression, relying on inflammatory factors and cells that 


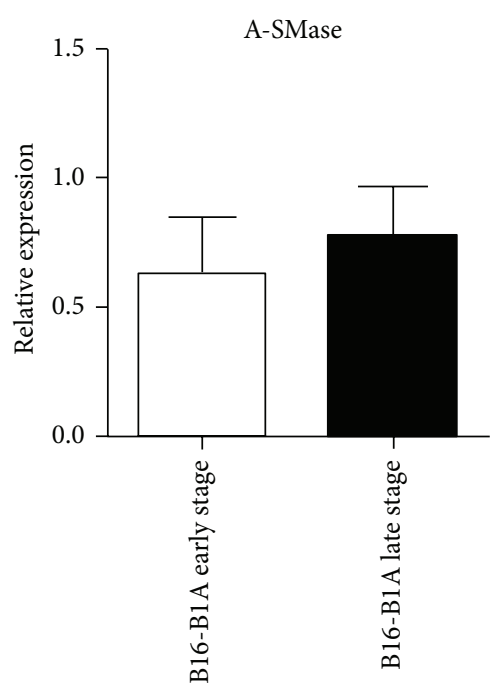

(a)
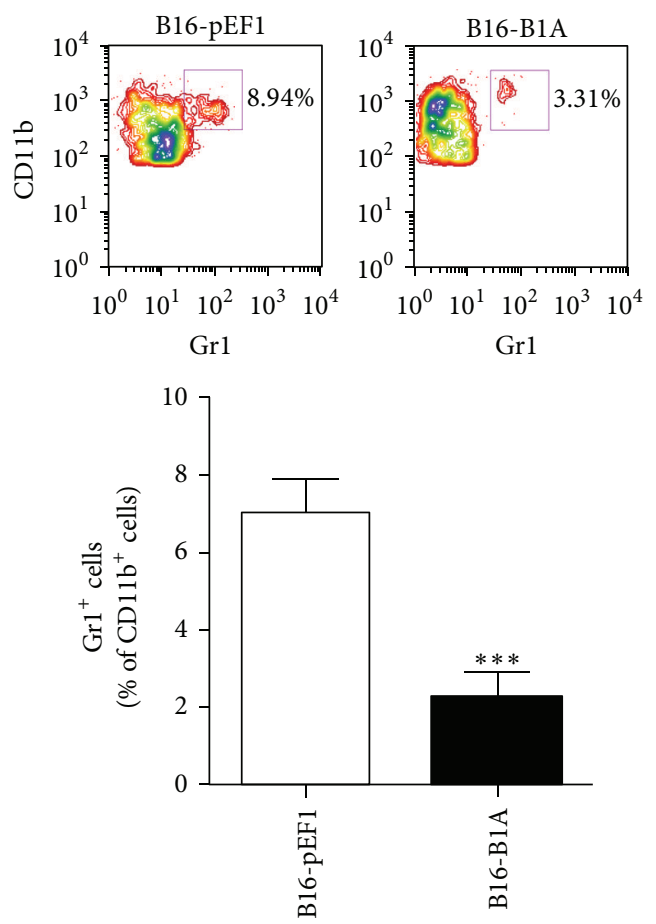

(b)
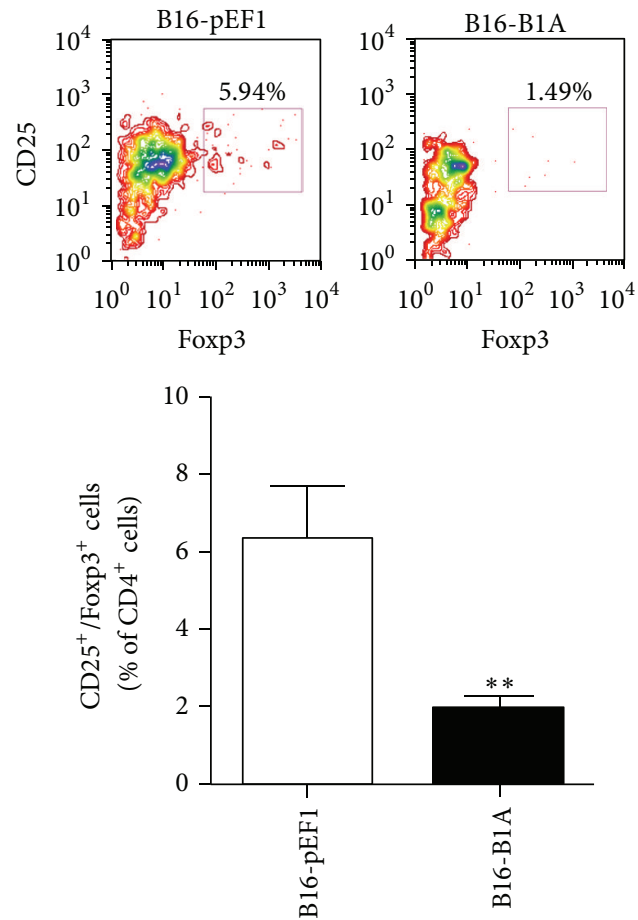

(c)

FIGURE 4: A-SMase expression reprogrammes the tumour microenvironment. (a) Analysis of A-SMase expression in B1A tumours in vivo. Tumours were resected when they reached the volume of ca. $500 \mathrm{~mm}^{3}$ (early stage) or $1500 \mathrm{~mm}^{3}$. A-SMase expression was evaluated by qPCR. The histograms represent the data obtained from five to seven animals per experimental group. (b-c) Flow cytometry analysis of tumourinfiltrating immune cells. Tumour cell suspensions obtained from resected tumours were stained with the specific fluorescent conjugated

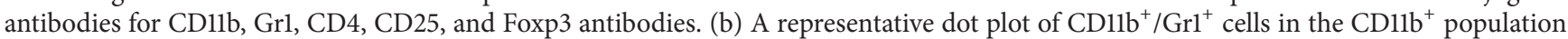
cell is shown (upper panel). The histograms represent the data obtained from ten to fifteen animals per experimental group (lower panel). (c) A representative dot plot of $\mathrm{CD} 25^{+} / \mathrm{Foxp}^{+}$in the $\mathrm{CD} 4^{+}$cell population is shown (upper panel). The histograms represent the data obtained from ten to fifteen animals per experimental group (lower panel). Values in each histogram are expressed as mean \pm SEM. ${ }^{* *} P<0.01$ versus B16-pEF1 control. 


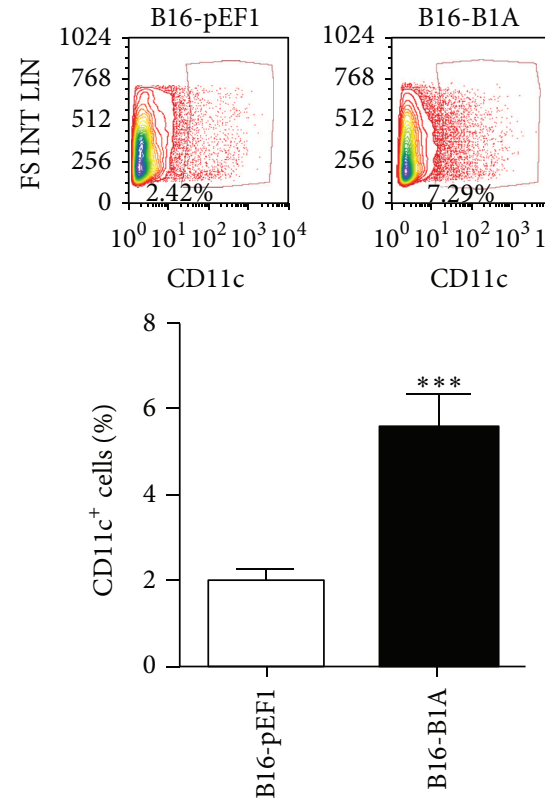

(a)
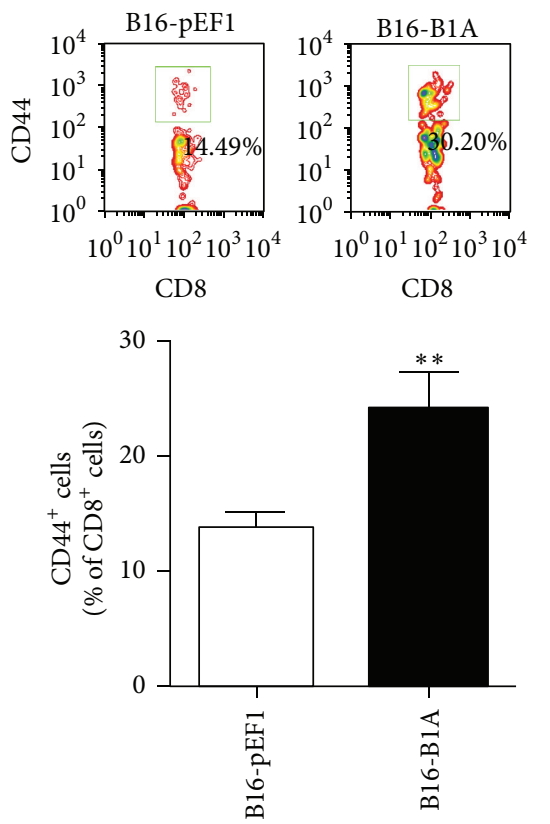

(d)

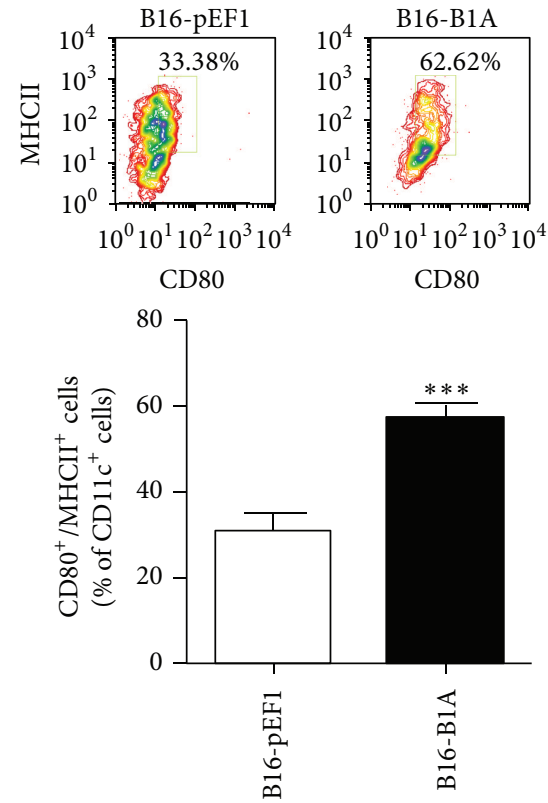

(b)
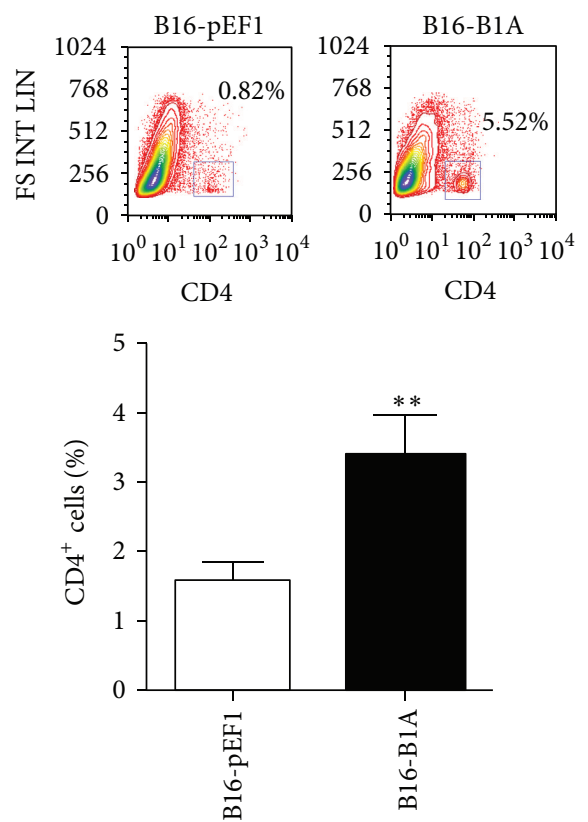

(e)
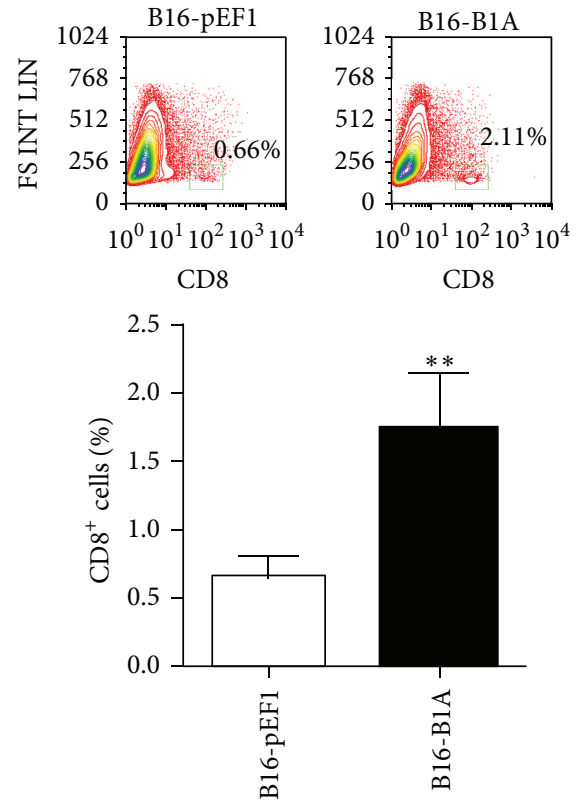

(c)
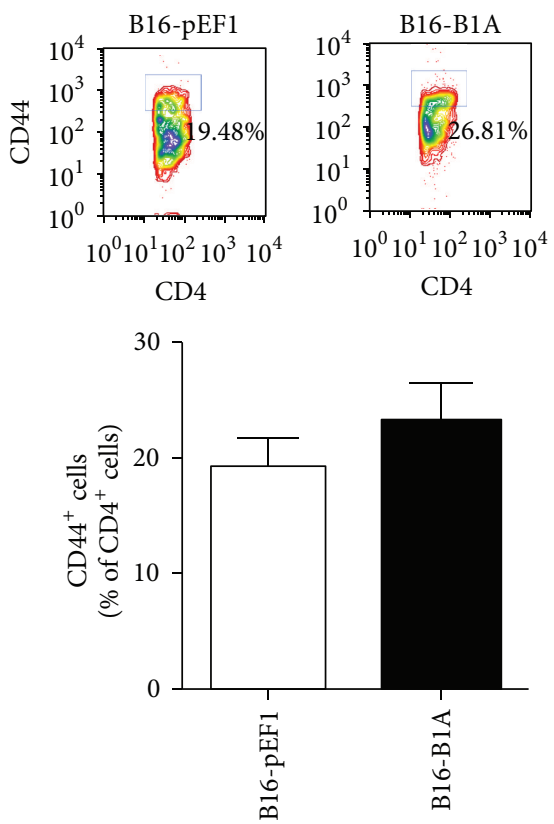

(f)

FIGURE 5: A-SMase expression increases the recruitment of effector antitumoural immune cells. Flow cytometry analysis of tumourinfiltrating immune cells. Tumour cell suspensions obtained from resected tumours were stained with the specific fluorescent conjugated antibodies for CD11c, CD80, MHCII, CD8, CD4, and CD44 antibodies. (a) A representative dot plot of gated CD11c ${ }^{+}$cells is shown (upper panel). The histograms represent the data obtained from ten to fifteen animals per experimental group (lower panel). (b) A representative dot plot of $\mathrm{CD} 0^{+} / \mathrm{MHCII}^{+}$cells in the $\mathrm{CD}_{11 c^{+}}$cell population is shown (upper panel). The histograms represent the data obtained from ten to fifteen animals per experimental group (lower panel). (c) A representative dot plot of CD $8^{+}$cells is shown (upper panel). The histograms represent the data obtained from ten to fifteen animals per experimental group (lower panel). (d) A representative dot plot of CD $8^{+} / \mathrm{CD} 44^{+}$ in the $\mathrm{CD}^{+}$cell population is shown (upper panel). The histograms represent the data obtained from ten to fifteen animals per experimental group (lower panel). (e) A representative dot plot of $\mathrm{CD} 4^{+}$cells is shown (upper panel). (f) A representative dot plot of $\mathrm{CD} 4^{+} / \mathrm{CD} 44^{+}$in the $\mathrm{CD} 4^{+}$cell population is shown (upper panel). The histograms represent the data obtained from ten to fifteen animals per experimental group (lower panel). Values in each histogram are expressed as mean \pm SEM. ${ }^{*} P<0.05$; ${ }^{* *} P<0.01$ versus B16-pEF1 control. 


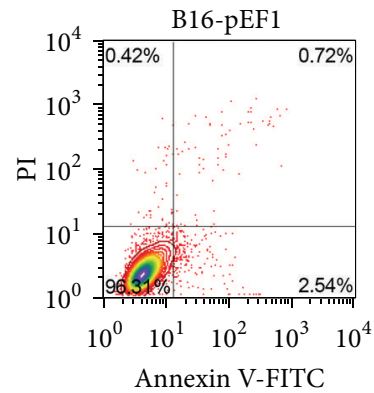

(a)

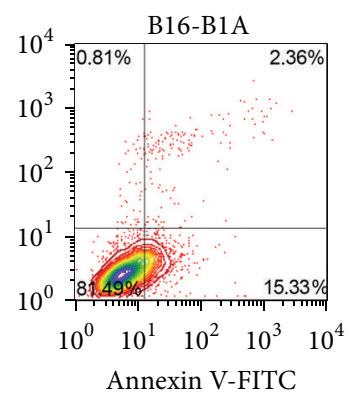

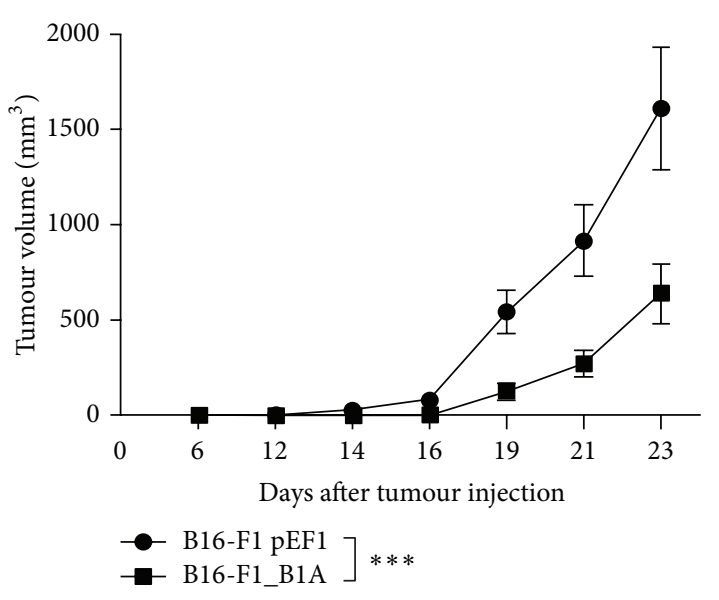

(b)

FIgure 6: A-SMase expression reduces tumour growth. (a) Flow cytometry analysis of cell death of B16-pEF1 and B16-B1A cells. Apoptosis/necrosis were evaluated by the double staining with annexin V-FITC and PI. A representative dot plot for each cell clone is shown $(n=3)$. (b) Tumour growth analysis. BC57BL/6 mice (10 animals per group) were injected in the right flank with B16-pEF1 and B16-B1A $\left(5 \times 10^{4}\right.$ cells). Tumour growth was monitored by measuring tumour volume $\left(\mathrm{mm}^{3}\right)$ every $2-3$ days. Values are expressed as mean \pm SEM. ${ }^{* * *} P<0.001$.

contribute to cell transformation, support cancerous cell survival, resist immunological destruction, and facilitate invasion and metastasis $[6,34]$. In keeping with the notion that the protumoural microenvironment can be considered the product of a developing cross talk between cancerous cells and stromal cells, here we demonstrate a close correlation between the extent and type of tumour infiltrate and A-SMase levels. Specifically, low A-SMase in melanoma accounts for the high expression of factors involved in inflammation (i.e., IL-1 $\beta$, IL-6, GM-CSF, and TNF- $\alpha$ ), which have been positively associated with cancer onset and progression $[6,34]$. In contrast with the A-SMase-mediated inhibitory effect on proinflammatory cytokines we also found that low A-SMase in melanoma accounts for the high expression of the anti-inflammatory cytokines IL-10 and TGF$\beta 1$. Of interest, both cytokines are generally accepted as major immunosuppressive cytokines expressed in tumours including melanoma, although there is still a debate on their effective role in antitumour immune response [6,34-38]. Our data indicate that A-SMase decrease in melanoma accounts for the establishment of a high immunosuppressive and protumoural microenvironment. In this respect, tumours with low A-SMase levels, that is, B16-F1_psil10 and B16-F1 at late stage of development, display an increase of MDSCs infiltration, already known to be responsible for the establishment of immunosuppression [5, 39]. MDSCs accumulation in the tumour mass determines the impairment of DCs and cytotoxic T lymphocytes $[25,27]$ and the recruitment of regulatory Tregs [40]. In this line, in low A-SMase expressing tumours we found low levels of DCs; of interest these cells also showed an immature and anergic phenotype, a typical feature of melanoma infiltrating DCs resulting in the inability to trigger the activation of tumour specific $\mathrm{CD}^{+}$and $\mathrm{CD}^{+}{ }^{+} \mathrm{T}$ lymphocytes [41, 42]. Moreover low A-SMase expressing tumours displayed increased Treg infiltration which is often associated with poor clinical outcome and tumour progression in different cancers [43]. This led to the hypothesis that the naturally occurring A-SMase decrease in melanoma cells during tumour progression contributes to the induction of immune tolerance and immunosuppression in tumour microenvironment and eventually in the acquisition of the high aggressive behaviour of melanoma in vivo [18].

In support of this hypothesis, the restoration of ASMase expression in melanoma cells not only reduces tumour growth and immunosuppression, but also accounts for a high recruitment in the tumour microenvironment of effector immune cells with an antitumoural function. Indeed, we observed a poor homing of MDSCs and Tregs in tumours in which a sustained expression of A-SMase is maintained during their progression, that is, B16-B1A. As a consequence, we observed the increased recruitment of $\mathrm{CD}^{+}$and $\mathrm{CD} 4^{+} \mathrm{T}$ lymphocytes at the tumour lesion and especially the infiltration of mature DCs and $\mathrm{CD} 8^{+} / \mathrm{CD} 44^{\text {high }}$ memory/activated T lymphocytes [44-46]. The accumulation of effector immune cells such as DCs and $\mathrm{CD}^{+}{ }^{+} \mathrm{T}$ lymphocytes into primary tumour lesions is associated with prolonged survival and a reduced incidence of metastases in patients with several types of solid cancer, including primary cutaneous melanomas $[47,48]$. Based on this evidence, the current preclinical and clinical studies regarding melanoma immunotherapy are centred on the administration of DCs or $\mathrm{CD}^{+}$cells in the form of $\mathrm{DC}$ vaccines or adoptive $\mathrm{T}$ cell transfer, preceded by radiotherapy or chemotherapy to induce lymphodepletion and the ensuing elimination of immunosuppressive MDSCs and Tregs [49-52]. Consistent with these reports, our findings on the role of A-SMase upregulation in reprogramming the status of tumour microenvironment open new vistas in therapeutic perspective. In particular, the possibility that A-SMase overexpression "educates" tumour microenvironment against cancer cells encourages the use of 
therapeutic approaches to increase the enzyme expression/ activity. This would create an antitumoural microenvironment suitable either for triggering an appropriate adaptive immune response against melanoma or for improving the efficacy of other immunotherapy strategies. In this respect, restoring A-SMase in melanomas by genetic overexpression or by recombinant protein administration, a protocol currently under examination for Niemann-Pick type B patients [53], might be considered a useful adjuvant for cancer therapy.

\section{Conclusion}

The evaluation of the role of A-SMase in many pathophysiological processes is a developing field [14, 28, 54-61]. This study demonstrates for the first time the central role of ASMase expressed by melanoma cells in orchestrating the cross talk with the surrounding microenvironment. These interactions are crucial for tumour fate, lying on its rejection or progression. The discovery of this A-SMase function exerted on the tumour-infiltrating immune cells suggests that the antineoplastic effect of the enzyme goes beyond the wellestablished role in cancer cell death but involves a more complex network that may be taken into consideration in the setting of therapeutic strategies.

\section{Conflict of Interests}

The authors declare that there is no conflict of interests regarding the publication of this paper.

\section{Acknowledgments}

This work was supported by "Ministero della Salute, Giovani Ricercatori 2011-2012" grant to Clara De Palma and "Ricerca Corrente 2015" grant to Emilio Clementi, "Ministero dell'Istruzione, Università e Ricerca, PRIN2010-2011” grants to Emilio Clementi and Davide Cervia, "Università di Milano, Giovani Ricercatori-Linea B” grant to Cristiana Perrotta, and "Associazione Italiana Ricerca sul Cancro (AIRC) IG11365" grant to Emilio Clementi.

\section{References}

[1] D. Grossman and D. C. Altieri, "Drug resistance in melanoma: mechanisms, apoptosis, and new potential therapeutic targets," Cancer and Metastasis Reviews, vol. 20, no. 1-2, pp. 3-11, 2001.

[2] A. H. Enk, J. C. Becker, and G. Schuler, "Immunotherapy of malignant melanoma-basic principles and novel therapeutic approaches," Journal der Deutschen Dermatologischen Gesellschaft, vol. 4, no. 8, pp. 635-645, 2006.

[3] R. Wu, M.-A. Forget, J. Chacon et al., "Adoptive T-cell therapy using autologous tumor-infiltrating lymphocytes for metastatic melanoma: current status and future outlook," The Cancer Journal, vol. 18, no. 2, pp. 160-175, 2012.

[4] V. Umansky, A. Sevko, C. Gebhardt, and J. Utikal, "Myeloidderived suppressor cells in malignant melanoma," Journal der Deutschen Dermatologischen Gesellschaft, vol. 12, no. 11, pp. 1021-1027, 2014.
[5] C. Meyera, A. Sevko, M. Ramacher et al., "Chronic inflammation promotes myeloid-derived suppressor cell activation blocking antitumor immunity in transgenic mouse melanoma model," Proceedings of the National Academy of Sciences of the United States of America, vol. 108, no. 41, pp. 17111-17116, 2011.

[6] S. I. Grivennikov, F. R. Greten, and M. Karin, "Immunity, inflammation, and cancer," Cell, vol. 140, no. 6, pp. 883-899, 2010.

[7] A. A. Navarini-Meury and C. Conrad, "Melanoma and innate immunity-active inflammation or just erroneous attraction?: melanoma as the source of leukocyte-attracting chemokines," Seminars in Cancer Biology, vol. 19, no. 2, pp. 84-91, 2009.

[8] K. N. Kodumudi, A. Weber, A. A. Sarnaik, and S. Pilon-Thomas, "Blockade of myeloid-derived suppressor cells after induction of lymphopenia improves adoptive T cell therapy in a murine model of melanoma," Journal of Immunology, vol. 189, no. 11, pp. 5147-5154, 2012.

[9] R. Wesolowski, J. Markowitz, and W. E. Carson III, "Myeloid derived suppressor cells-a new therapeutic target in the treatment of cancer," Journal for ImmunoTherapy of Cancer, vol. 1, article 10, 2013.

[10] B. Ogretmen and Y. A. Hannun, "Biologically active sphingolipids in cancer pathogenesis and treatment," Nature Reviews Cancer, vol. 4, no. 8, pp. 604-616, 2004.

[11] C. De Palma and C. Perrotta, "Ceramide as a target of chemotherapy: its role in apoptosis and autophagy," Clinical Lipidology, vol. 7, no. 1, pp. 111-119, 2012.

[12] L. Riboni, R. Campanella, R. Bassi et al., "Ceramide levels are inversely associated with malignant progression of human glial tumors," Glia, vol. 39, no. 2, pp. 105-113, 2002.

[13] A. Prinetti, D. Millimaggi, S. D’Ascenzo et al., "Lack of ceramide generation and altered sphingolipid composition are associated with drug resistance in human ovarian carcinoma cells," Biochemical Journal, vol. 395, no. 2, pp. 311-318, 2006.

[14] E. L. Smith and E. H. Schuchman, "The unexpected role of acid sphingomyelinase in cell death and the pathophysiology of common diseases," The FASEB Journal, vol. 22, no. 10, pp. 34193431, 2008.

[15] A. E. M. Mahdy, J. C. Cheng, J. Li et al., "Acid ceramidase upregulation in prostate cancer cells confers resistance to radiation: AC inhibition, a potential radiosensitizer," Molecular Therapy, vol. 17, no. 3, pp. 430-438, 2009.

[16] V. Edmond, F. Dufour, G. Poiroux et al., "Downregulation of ceramide synthase- 6 during epithelial-to-mesenchymal transition reduces plasma membrane fluidity and cancer cell motility," Oncogene, vol. 34, no. 19, pp. 996-1005, 2014.

[17] N. H. T. Petersen, O. D. Olsen, L. Groth-Pedersen et al., "Transformation-associated changes in sphingolipid metabolism sensitize cells to lysosomal cell death induced by inhibitors of acid sphingomyelinase," Cancer Cell, vol. 24, no. 3, pp. 379-393, 2013.

[18] L. Bizzozero, D. Cazzato, D. Cervia et al., "Acid sphingomyelinase determines melanoma progression and metastatic behaviour via the microphtalmia-associated transcription factor signalling pathway," Cell Death and Differentiation, vol. 21, no. 4, pp. 507-520, 2013.

[19] C. Perrotta, L. Bizzozero, S. Falcone et al., "Nitric oxide boosts chemoimmunotherapy via inhibition of acid sphingomyelinase in a mouse model of melanoma," Cancer Research, vol. 67, no. 16, pp. 7559-7564, 2007.

[20] C. Perrotta, M. Buldorini, E. Assi et al., "The thyroid hormone triiodothyronine controls macrophage maturation and 
functions: protective role during inflammation," The American Journal of Pathology, vol. 184, no. 1, pp. 230-247, 2014.

[21] C. de Palma, F. Morisi, S. Pambianco et al., "Deficient nitric oxide signalling impairs skeletal muscle growth and performance: involvement of mitochondrial dysregulation," Skeletal Muscle, vol. 4, article 22, 2014.

[22] D. Cazzato, E. Assi, C. Moscheni et al., "Nitric oxide drives embryonic myogenesis in chicken through the upregulation of myogenic differentiation factors," Experimental Cell Research, vol. 320, no. 2, pp. 269-280, 2014.

[23] C. Sciorati, T. Touvier, R. Buono et al., "Necdin is expressed in cachectic skeletal muscle to protect fibers from tumor-induced wasting," Journal of Cell Science, vol. 122, part 8, pp. 1119-1125, 2009.

[24] M. Opreanu, M. Tikhonenko, S. Bozack et al., "The unconventional role of acid sphingomyelinase in regulation of retinal microangiopathy in diabetic human and animal models," Diabetes, vol. 60, no. 9, pp. 2370-2378, 2011.

[25] G. Schiavoni, L. Gabriele, and F. Mattei, "The tumor microenvironment: a pitch for multiple players," Frontiers in Oncology, vol. 3, article 90, 2013.

[26] P. C. Rodriguez, D. G. Quiceno, and A. C. Ochoa, "Larginine availability regulates T-lymphocyte cell-cycle progression," Blood, vol. 109, no. 4, pp. 1568-1573, 2007.

[27] S. Ostrand-Rosenberg, P. Sinha, D. W. Beury, and V. K. Clements, "Cross-talk between myeloid-derived suppressor cells (MDSC), macrophages, and dendritic cells enhances tumor-induced immune suppression," Seminars in Cancer Biology, vol. 22, no. 4, pp. 275-281, 2012.

[28] E. Gulbins and R. Kolesnick, "Raft ceramide in molecular medicine," Oncogene, vol. 22, no. 45, pp. 7070-7077, 2003.

[29] S. Lacour, A. Hammann, S. Grazide et al., "Cisplatin-induced CD95 redistribution into membrane lipid rafts of HT29 human colon cancer cells," Cancer Research, vol. 64, no. 10, pp. 35933598, 2004.

[30] S. Brunelli, C. Sciorati, G. D’Antona et al., "Nitric oxide release combined with nonsteroidal antiinflammatory activity prevents muscular dystrophy pathology and enhances stem cell therapy," Proceedings of the National Academy of Sciences of the United States of America, vol. 104, no. 1, pp. 264-269, 2007.

[31] Y. H. Zeidan and Y. A. Hannun, "Activation of acid sphingomyelinase by protein kinase Cdelta-mediated phosphorylation," The Journal of Biological Chemistry, vol. 282, no. 15, pp. 11549-11561, 2007.

[32] M. Garcia-Barros, D. Lacorazza, H. Petrie et al., "Host acid sphingomyelinase regulates microvascular function not tumor immunity," Cancer Research, vol. 64, no. 22, pp. 8285-8291, 2004.

[33] E. L. Smith and E. H. Schuchman, "Acid sphingomyelinase overexpression enhances the antineoplastic effects of irradiation in vitro and in vivo," Molecular Therapy, vol. 16, no. 9, pp. 15651571, 2008.

[34] J. Kanterman, M. Sade-Feldman, and M. Baniyash, "New insights into chronic inflammation-induced immunosuppression," Seminars in Cancer Biology, vol. 22, no. 4, pp. 307-318, 2012.

[35] S.-K. Leivonen and V.-M. Kähäri, "Transforming growth factor$\beta$ signaling in cancer invasion and metastasis," International Journal of Cancer, vol. 121, no. 10, pp. 2119-2124, 2007.

[36] J. Kim, R. L. Modlin, R. L. Moy et al., "IL-10 production in cutaneous basal and squamous cell carcinomas: a mechanism for evading the local $\mathrm{T}$ cell immune response," Journal of Immunology, vol. 155, no. 4, pp. 2240-2247, 1995.

[37] S. Mocellin, F. M. Marincola, and H. A. Young, "Interleukin10 and the immune response against cancer: a counterpoint," Journal of Leukocyte Biology, vol. 78, no. 5, pp. 1043-1051, 2005.

[38] S. Tikoo and N. K. Haass, "Friends or foes: IL-10 and TGFbeta in melanoma," Experimental Dermatology, vol. 24, no. 4, pp. 254-255, 2015.

[39] V. Umansky and A. Sevko, "Melanoma-induced immunosuppression and its neutralization," Seminars in Cancer Biology, vol. 22, no. 4, pp. 319-326, 2012.

[40] E. Schlecker, A. Stojanovic, C. Eisen et al., "Tumor-infiltrating monocytic myeloid-derived suppressor cells mediate CCR5dependent recruitment of regulatory $\mathrm{T}$ cells favoring tumor growth," Journal of Immunology, vol. 189, no. 12, pp. 5602-5611, 2012.

[41] P. Stoitzner, L. K. Green, J. Y. Jung et al., "Inefficient presentation of tumor-derived antigen by tumor-infiltrating dendritic cells," Cancer Immunology, Immunotherapy, vol. 57, no. 11, pp. 16651673, 2008.

[42] H. Ataera, E. Hyde, K. M. Price, P. Stoitzner, and F. Ronchese, "Murine melanoma-infiltrating dendritic cells are defective in antigen presenting function regardless of the presence of CD4+CD25+ regulatory T cells," PLoS ONE, vol. 6, no. 3, Article ID e17515, 2011.

[43] W. Zou, "Regulatory $\mathrm{T}$ cells, tumour immunity and immunotherapy," Nature Reviews Immunology, vol. 6, no. 4, pp. 295-307, 2006.

[44] M. J. Dobrzanski, J. B. Reome, and R. W. Dutton, “Type 1 and type $2 \mathrm{CD}^{+}$effector T cell subpopulations promote longterm tumor immunity and protection to progressively growing tumor," Journal of Immunology, vol. 164, no. 2, pp. 916-925, 2000.

[45] B. J. G. Baaten, C.-R. Li, and L. M. Bradley, "Multifaceted regulation of T cells by CD44," Communicative and Integrative Biology, vol. 3, no. 6, pp. 508-512, 2010.

[46] R. W. Dutton, L. M. Bradley, and S. L. Swain, "T cell memory," Annual Review of Immunology, vol. 16, pp. 201-223, 1998.

[47] Y. Ma, G. V. Shurin, Z. Peiyuan, and M. R. Shurin, "Dendritic cells in the cancer microenvironment," Journal of Cancer, vol. 4 , no. 1, pp. 36-44, 2013.

[48] O. Preynat-Seauve, P. Schuler, E. Contassot, F. Beermann, B. Huard, and L. E. French, "Tumor-infiltrating dendritic cells are potent antigen-presenting cells able to activate $\mathrm{T}$ cells and mediate tumor rejection," Journal of Immunology, vol. 176, no. 1, pp. 61-67, 2006.

[49] F. Benencia, L. Sprague, J. McGinty, M. Pate, and M. Muccioli, "Dendritic cells the tumor microenvironment and the challenges for an effective antitumor vaccination," Journal of Biomedicine and Biotechnology, vol. 2012, Article ID 425476, 15 pages, 2012.

[50] C. P. Duong, C. S. Yong, M. H. Kershaw, C. Y. Slaney, and P. K. Darcy, "Cancer immunotherapy utilizing gene-modified T cells: from the bench to the clinic," Molecular Immunology, 2015.

[51] O. Itzhaki, D. Levy, D. Zikich et al., "Adoptive T-cell transfer in melanoma," Immunotherapy, vol. 5, no. 1, pp. 79-90, 2013.

[52] G. Q. Phan and S. A. Rosenberg, "Adoptive cell transfer for patients with metastatic melanoma: the potential and promise of cancer immunotherapy," Cancer Control, vol. 20, no. 4, pp. 289-297, 2013. 
[53] J. M. Murray, A. M. Thompson, A. Vitsky et al., "Nonclinical safety assessment of recombinant human acid sphingomyelinase (rhASM) for the treatment of acid sphingomyelinase deficiency: the utility of animal models of disease in the toxicological evaluation of potential therapeutics," Molecular Genetics and Metabolism, vol. 114, no. 2, pp. 217-225, 2015.

[54] C. Perrotta and E. Clementi, "Biological roles of acid and neutral sphingomyelinases and their regulation by nitric oxide," Physiology, vol. 25, no. 2, pp. 64-71, 2010.

[55] D. Cervia, C. Perrotta, C. Moscheni, C. de Palma, and E. Clementi, "Nitric oxide and sphingolipids control apoptosis and autophagy with a significant impact on Alzheimer's disease," Journal of Biological Regulators and Homeostatic Agents, vol. 27, no. 2, supplement, pp. 11-22, 2013.

[56] E. Assi, D. Cazzato, C. De Palma, C. Perrotta, E. Clementi, and D. Cervia, "Sphingolipids and brain resident macrophages in neuroinflammation: an emerging aspect of nervous system pathology," Clinical and Developmental Immunology, vol. 2013, Article ID 309302, 8 pages, 2013.

[57] C. Perrotta, L. Bizzozero, D. Cazzato et al., "Syntaxin 4 is required for acid sphingomyelinase activity and apoptotic function," Journal of Biological Chemistry, vol. 285, no. 51, pp. 40240-40251, 2010.

[58] Y. Li, S. Li, X. Qin et al., "The pleiotropic roles of sphingolipid signaling in autophagy," Cell Death and Disease, vol. 5, no. 5, Article ID e1245, 2014.

[59] F. C. Luft, "Acid sphingomyelinase, autophagy, and atherosclerosis," Journal of Molecular Medicine, vol. 92, no. 5, pp. 429-431, 2014.

[60] C. Garcia-Ruiz, J. M. Mato, D. Vance, N. Kaplowitz, and J. C. Fernández-Checa, "Acid sphingomyelinase-ceramide system in steatohepatitis: a novel target regulating multiple pathways," Journal of Hepatology, vol. 62, no. 1, pp. 219-233, 2015.

[61] C. Perrotta, D. Cervia, C. de Palma et al., "The emerging role of Acid Sphingomyelinase in autophagy," Apoptosis, vol. 20, no. 5, pp. 635-644, 2015. 


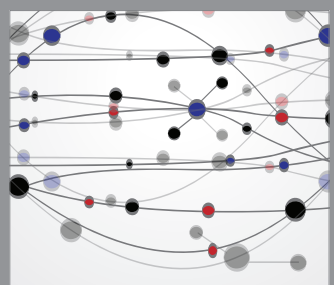

The Scientific World Journal
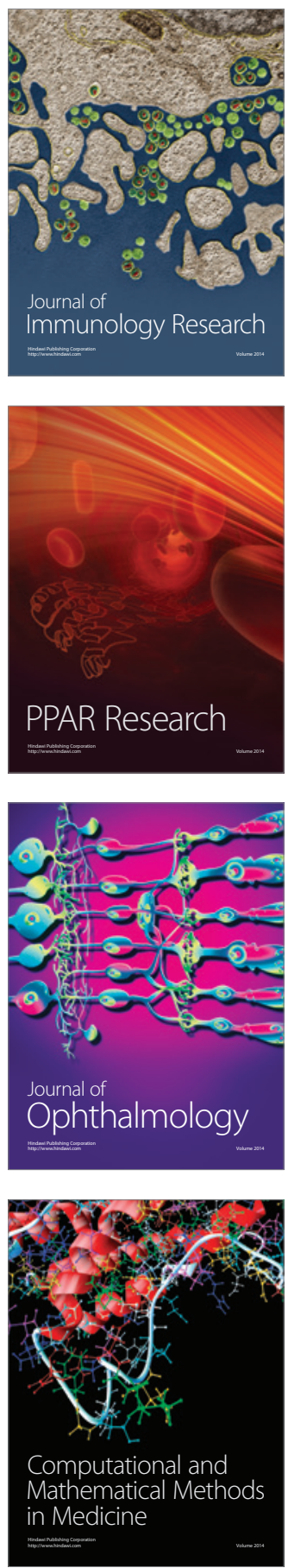

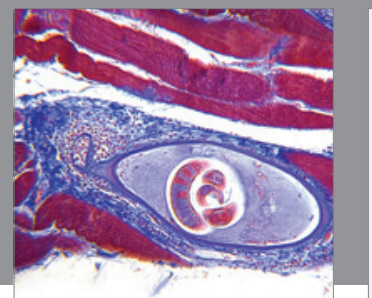

Gastroenterology

Research and Practice
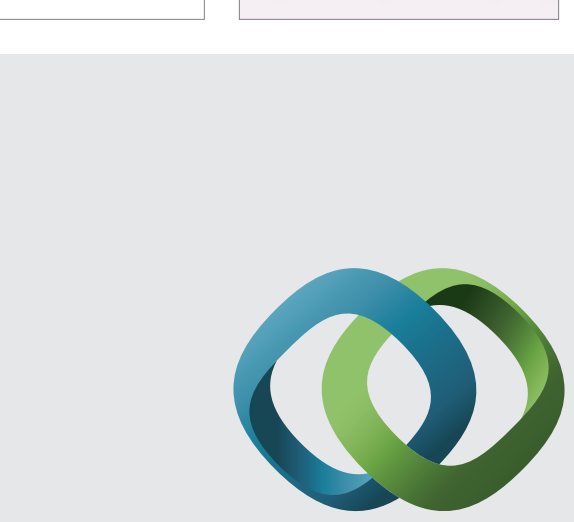

\section{Hindawi}

Submit your manuscripts at

http://www.hindawi.com
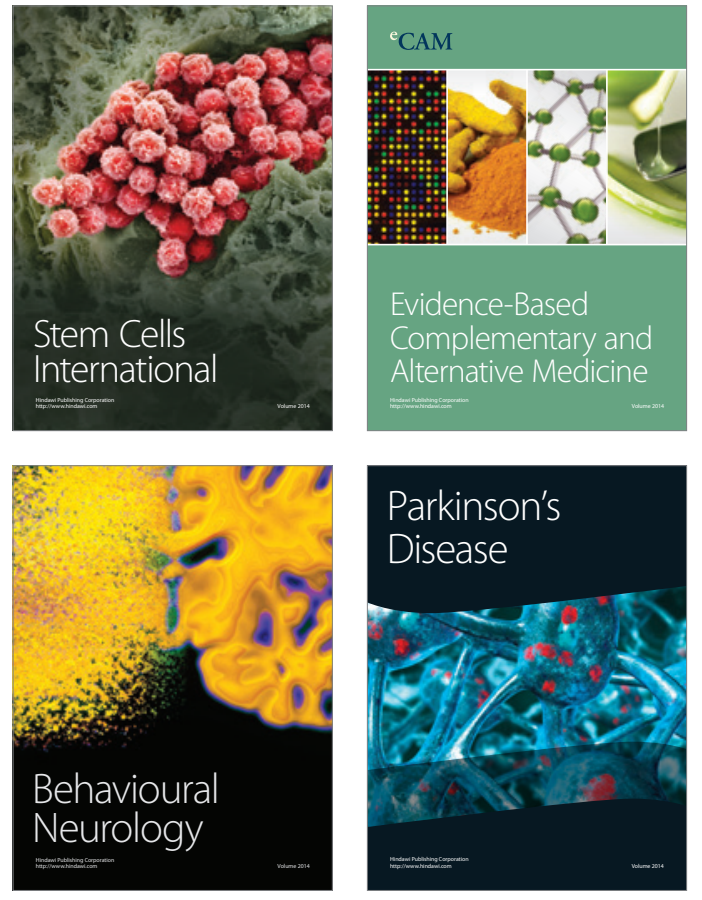
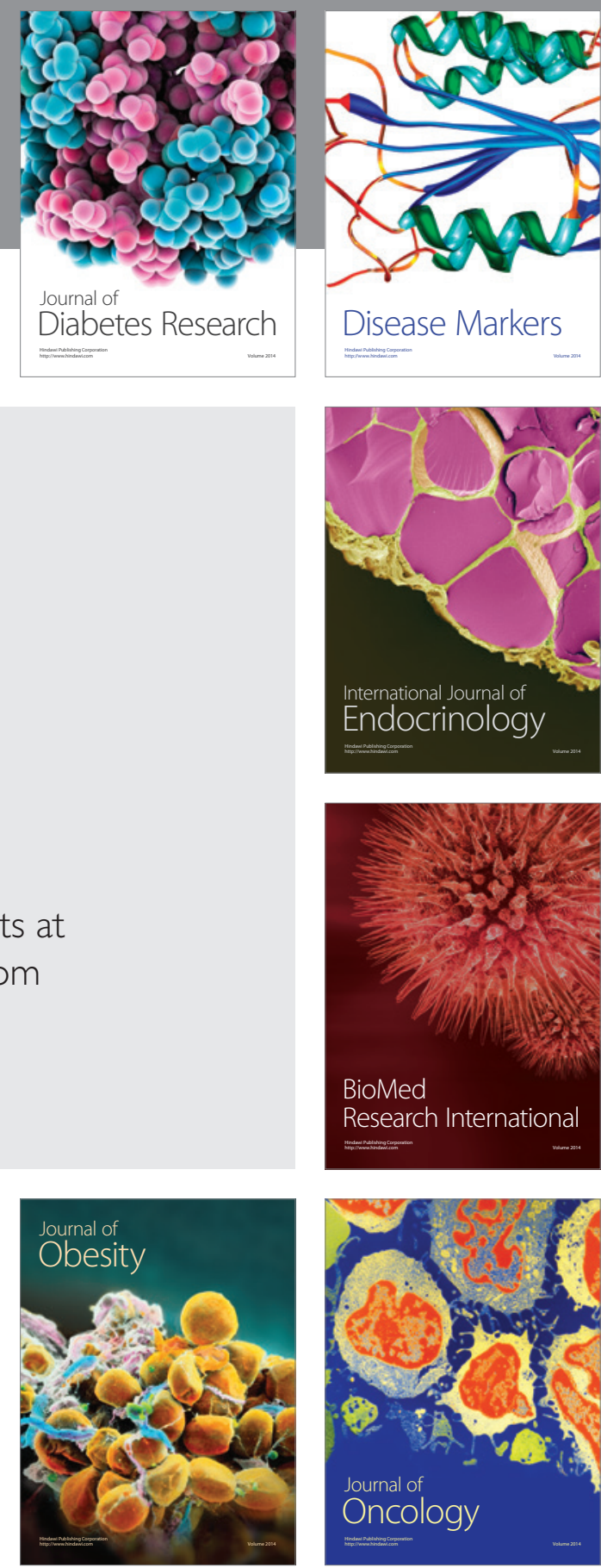

Disease Markers
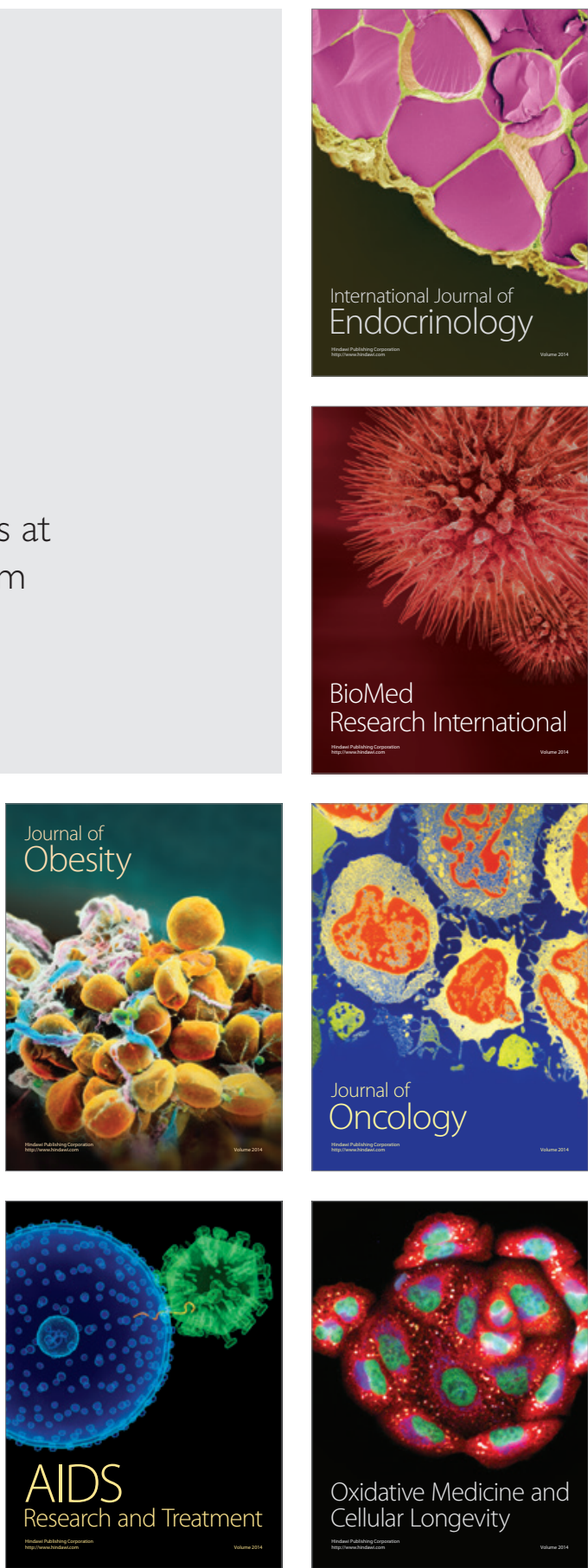